\title{
Flame Spread and Extinction Over a Thick Solid Fuel in Low-Velocity Opposed and Concurrent Flows
}

\author{
Feng $\mathrm{Zhu}^{1} \cdot$ Zhanbin $\mathrm{Lu}^{2} \cdot$ Shuangfeng Wang ${ }^{1}$
}

Received: 24 June 2015 / Accepted: 5 November 2015 / Published online: 25 November 2015

(C) Springer Science+Business Media Dordrecht 2015

\begin{abstract}
Flame spread and extinction phenomena over a thick PMMA in purely opposed and concurrent flows are investigated by conducting systematical experiments in a narrow channel apparatus. The present tests focus on lowvelocity flow regime and hence complement experimental data previously reported for high and moderate velocity regimes. In the flow velocity range tested, the opposed flame is found to spread much faster than the concurrent flame at a given flow velocity. The measured spread rates for opposed and concurrent flames can be correlated by corresponding theoretical models of flame spread, indicating that existing models capture the main mechanisms controlling the flame spread. In low-velocity gas flows, however, the experimental results are observed to deviate from theoretical predictions. This may be attributed to the neglect of radiative heat loss in the theoretical models, whereas radiation becomes important for low-intensity flame spread. Flammability limits using oxygen concentration and flow velocity as coordinates are presented for both opposed and concurrent flame spread configurations. It is found that concurrent spread has a wider flammable range than opposed case. Beyond the flammability boundary of opposed spread, there is an additional flammable area for concurrent spread, where the spreading flame is sustainable in concurrent mode
\end{abstract}

Shuangfeng Wang

sfwang@imech.ac.cn

1 Key Laboratory of Microgravity, Institute of Mechanics, Chinese Academy of Sciences, Beijing 100190, China

2 Institute of Applied Mathematics and Mechanics, Shanghai University, Shanghai 200072, China only. The lowest oxygen concentration allowing concurrent flame spread in forced flow is estimated to be approximately $14 \% \mathrm{O}_{2}$, substantially below that for opposed spread $\left(18.5 \% \mathrm{O}_{2}\right)$.

Keywords Flame spread · Extinction limit - Thick fuel · Microgravity

\section{Introduction}

Flame spread over a thermally-thick solid fuel in oxidizer flow has been studied extensively during the past decades (e.g., de Ris 1969; Fernandez-Pello et al. 1981; Bhattacharjee et al. 1996). The phenomena result from the inherently complex interaction of heat and mass transport processes, and the chemical reaction in both gas and condensed phases. In order to generalize the results and to develop simplified theories, the flame spread phenomenon is normally classified into two modes: opposed flow spread when a flame spreads against the oxidizer flow, and concurrent spread when a flame spreads in the same direction as the oxidizer flow. Previous studies on flame spread over thermally-thick fuels have focused primarily on either opposed-flow mode or concurrent mode.

It is well known that the flame spread behavior in opposing or concurrent flows depends strongly on the magnitude of the flow velocity. Although the influence of high-velocity and moderate-velocity has been investigated by numerous experimental and theoretical works, few studies exist for gas velocities smaller than that induced by buoyant flow, such that little is known about flame spread over thick fuels in the low-velocity flow regime. This situation stems from the fact that, to eliminate the complications of buoyant flow, a microgravity environment is needed, and thick solids have 
longer time scales than thin solids, which precludes the use of ground-based facilities such as drop towers for a microgravity test. Most research on microgravity flame spread has dealt with thermally-thin fuels (T'ien et al. 2001).

The division of flame spread between opposed-flow and concurrent-flow is very meaningful in the sense that the dominant heat transfer mechanisms are different in the two model problems. Forward heat transfer is mainly by the gasphase conduction for opposed spread, whereas convection prevails for concurrent spread. Since convective heat transfer is generally more effective than conduction, concurrent spread is usually expected to be more rapid than opposed spread. As the flow velocity decreases, however, the relative effectiveness of the heat transfer mechanisms may be changed. Actually, microgravity experiments and numerical simulations (Olson et al. 1991, 2001; Kashiwagi et al. 1996; Kumar et al. 2003) revealed that, for thermally-thin fuels, the opposed flame can spread faster than the concurrent flame if the flow velocities are low enough. In the present work, flame spread phenomena over a thermallythick fuel are investigated experimentally for low-velocity opposed and concurrent flows, and a comparison of flame spread rates between the two flame spread modes are made.

For thermally-thin fuel, a steady flame spread can be achieved in a quiescent environment when the oxygen percentage is sufficiently high (Bhattacharjee and Altenkirch 1990; Ramachandra et al. 1995; Kumar et al. 2003), which is considered as a special case of opposed flame spread. However, the limiting flow velocity for steady concurrent flame spread to occur over a thin fuel is finite and does not go to zero. On the contrary, the microgravity experiments on thermally-thick fuels (PMMA plates) in a quiescent, $50 \%$ or $70 \% \mathrm{O}_{2}, 1 \mathrm{~atm}$ environment produced unsteady flames that extinguished by itself eventually (West et al. 1996; Altenkirch et al. 1998). Furthermore, the only microgravity experiment (Olson et al. 2004) where the opposed-flow flame spread over thermally-thick fuels in moving atmospheres was examined showed that, although the flame extinguished at $35 \% \mathrm{O}_{2}$ for a flow velocity of $1 \mathrm{~cm} / \mathrm{s}$, steady flame spread rates were achieved at $50 \%$ and $70 \% \mathrm{O}_{2}$ for the same flow velocity. So, the limited microgravity data suggest that, unlike thin fuels, there exists a limiting flow velocity for the opposed flame spread over thermally-thick fuels. In view of the above observations, our understanding of the low-velocity flame quenching behavior over thick fuels is far from mature. The problem requires further research on both two flame spread modes.

The present study is initiated in support of the microgravity experiment "Ignition and Burning of Solid Materials in Microgravity", which will be performed aboard the SJ-10 satellite of China in the end of 2015 or a bit later (Hu et al. 2014). By employing a narrow channel apparatus to suppress buoyant flow, systematical experiments are conducted to observe the flame propagation and extinction processes over a thick PMMA sample in opposed and concurrent flows, considering the influence of the small flow velocity and the oxygen concentration. The flame spread rates are measured as a function of the velocity and oxygen concentration of the forced gas flow. The experimental results are analyzed in the framework of existing theoretical models of flame spread, and the data for opposed flames are compared with those for concurrent flames. Flammability maps using oxygen concentration and flow velocity as coordinates are presented for both opposed and concurrent flames. A comparison of flammability limits between the two flame spread modes reveals their relative flammability in low-velocity flows. It is worth to note that various authors (Ivanov et al. 1999; Olson et al. 2009; Xiao et al. 2010; Zhang and Yu 2011) have utilized the narrow-channel type apparatus to suppress buoyancy and in effect capture the essential features of microgravity flame spread. Particularly, such an apparatus provides an abundant test time that is needed in the experiments of flame spread over thermally-thick fuels.

\section{Experimental Methods}

The experimental setup consists of a flow system, a horizontal narrow channel, video cameras, and a data-acquisition system. The narrow channel is $255 \mathrm{~mm}$ long, $360 \mathrm{~mm}$ wide and $10 \mathrm{~mm}$ high. For visualization purpose, the top and side walls of the channel are made of quartz glass. The flow system supplies gas flow from a high pressure gas bottle containing a specified $\mathrm{O}_{2}-\mathrm{N}_{2}$ mixture. During the test, the flow rate is controlled by a mass flow controller (Alicat Scientific, type MC). The metered gas flow enters a plenum chamber and passes through a honeycomb section before entering the test channel. The forced flow passes through the channel at atmospheric pressure, while the average velocity across the cross-section of the channel can be adjusted in a range of $0 \sim 15 \mathrm{~cm} / \mathrm{s}$.

The fuel used in the experiments is a $10 \mathrm{~mm}$ thick polymethylmethacrylate (PMMA) plate, measuring $60 \mathrm{~mm}$ long by $50 \mathrm{~mm}$ wide. As schematically shown in Fig. 1, the fuel sample is embedded in the aluminum floor of the test section, with its top face flushed with the floor and the side and bottom faces insulated from the floor. Ignition of the fuel is accomplished by energizing a resistively heated wire, and the ignition wire is embedded $2 \mathrm{~mm}$ from the downstream end of the sample in experiments on opposed flame spread, or $1.5 \mathrm{~mm}$ from the upstream end in concurrent flame spread experiments. Once ignited, the flame propagation takes place as a purely opposed mode or a purely concurrent mode, depending on the location of the ignition. The flame behaviors are recorded by two color digital video 
Fig. 1 Schematic of the horizontal narrow channel. $\mathrm{T} 1 \sim \mathrm{T} 4$ indicate the positions of the four thermocouples used in concurrent flame spread tests

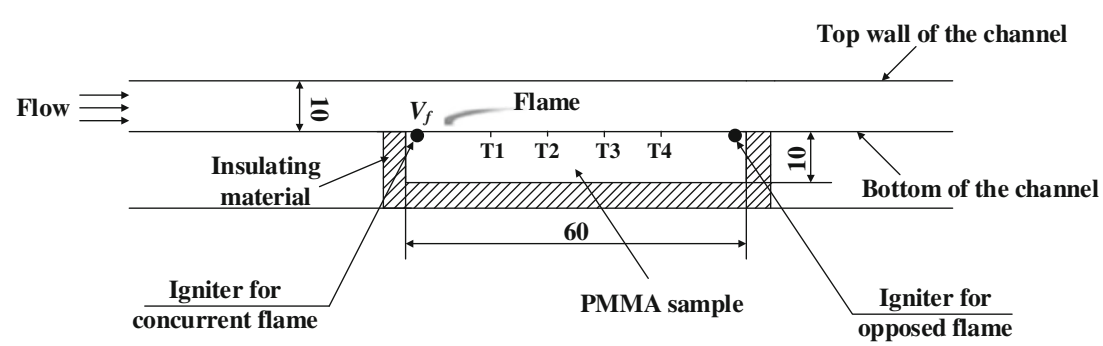

cameras (Sony DCR-TRV 900E, with a frame rate of 25 fps), of which one is mounted above the test section for top view, and the other placed laterally to capture the side view.

For the concurrent flame spread mode, another diagnostic is four surface thermocouples (type- $\mathrm{K}, 0.075 \mathrm{~mm}$ in diameter) embedded along the long dimension of the sample, which are located at distances of $10 \mathrm{~mm}$ apart downstream of the igniter. In the flame spread process, the data acquisition system records the surface temperature as a function of time. These temperature histories are used to determine the spread rate of the concurrent flame. More details of such a measuring method have been described in previous studies (Fernandez-Pello 1979; Loh and Fernandez-Pello 1984).

The experimental procedure is as follows. The gas flow is initiated first and is allowed to fully develop within the test channel. Then, the fuel sample is ignited by energizing the resistively heated wire. As soon as a uniform flame front is observed over the fuel surface, the igniter is turned off. During the entire test procedure, the two cameras capture the flame behaviors. In the tests of concurrent flame spread, the surface temperature dada are recorded as well.

The flow controller precision $( \pm 1 \%)$ provides a precision of $\pm 2 \%$ for the flow velocities in the experiments. The absolute error for the oxygen concentration is $\pm 1 \%$ in the reported values. The error on the measured flame spread rate is mainly due to the uncertainty of flame position measurements, and the maximum relative error is estimated to be $\pm 6 \%$.

\section{Results and Discussion}

\section{Flame Character in Opposed and Concurrent Spread Modes}

Figure 2a tabulates top view images of opposed spreading flames at different oxygen concentrations and gas flow velocities. It is evident that the leading edge of the flame is always blue-colored, although the color becomes diluted as the oxygen concentration decreases. With the increase of the flow velocity, notably at $U=8 \mathrm{~cm} / \mathrm{s}$, a bright-yellow trailing tail begins to develop behind the leading edge, resulting in a substantial increase of the flame length. At $21 \% \mathrm{O}_{2}$, when $U \leq 5 \mathrm{~cm} / \mathrm{s}$, the flames are observed to shrink lat- erally and become curve-shaped, with the convex surfaces facing upstream. Moreover, at $U=3 \mathrm{~cm} / \mathrm{s}$, the curved flame front even splits into two separate flamelets. One typical side-view flame image (at $21 \% \mathrm{O}_{2}$ and $U=8 \mathrm{~cm} / \mathrm{s}$ ) is given

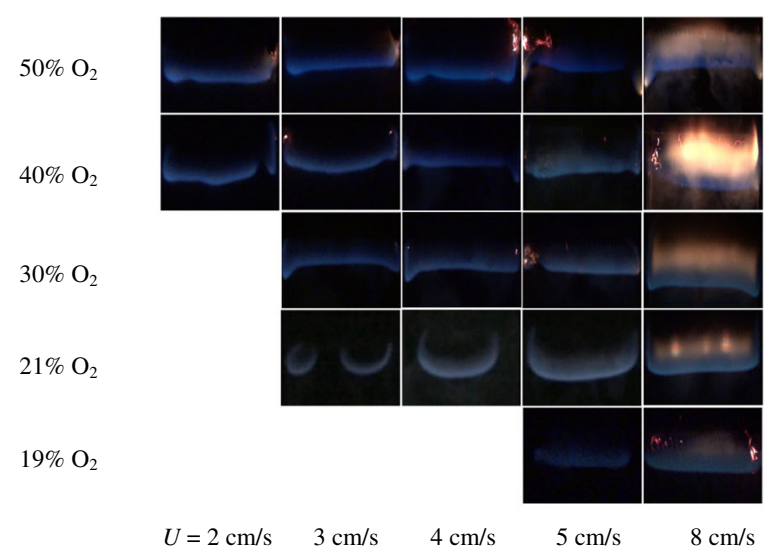

(a) Top view of opposed flame. The flow enters from bottom.

$21 \% \mathrm{O}_{2}$

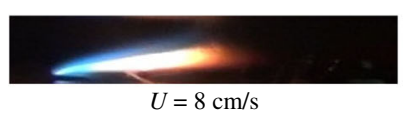

(b) Side view of opposed flame. The flow enters from left.

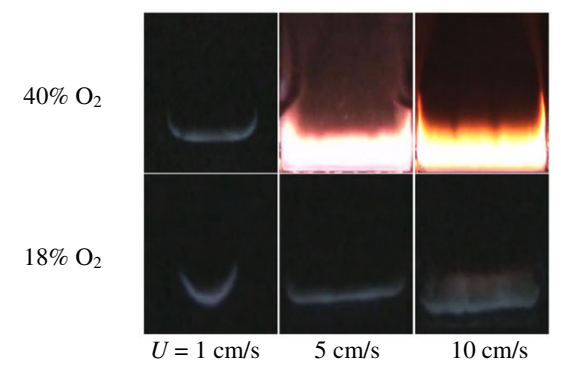

(c) Top view of concurrent flame. The flow enters from bottom.

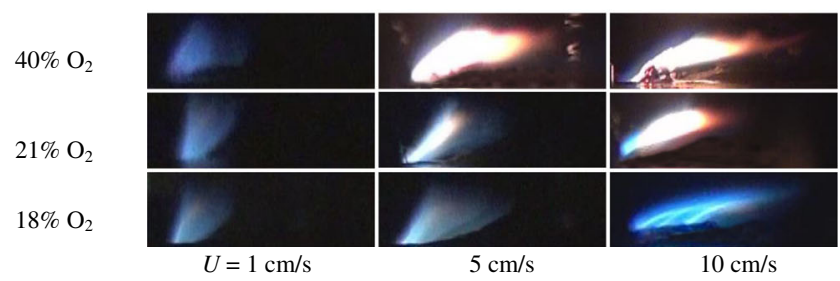

(d) Side view of concurrent flame. The flow enters from left.

Fig. 2 Images of flames spreading in opposed and concurrent gas flows 


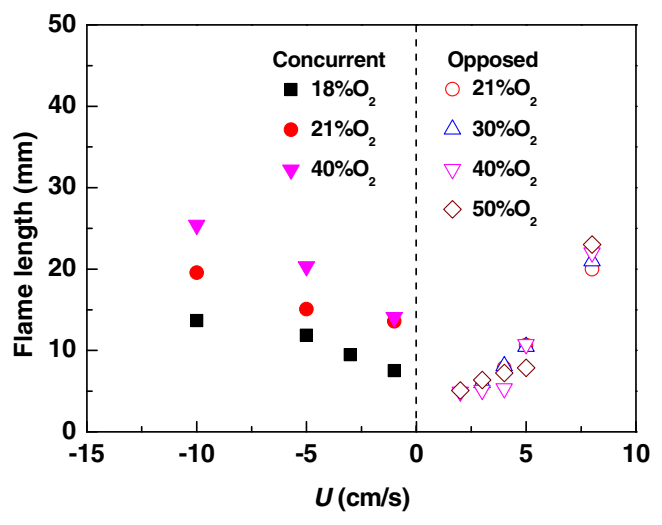

Fig. 3 Flame length as a function of flow velocity for opposed and concurrent spreading flames at different oxygen concentrations. The velocity of opposed flow is defined as positive, and concurrent flow as negative

in Fig. 2b, which clearly illustrates the color variation of the visible flame from its leading edge to trailing portion.

Top-view and side-view images of concurrent flames are shown in Fig. 2c and Fig. 2d, respectively. Generally speaking, the luminance of the flame increases with the increase of flow velocity and/or oxygen concentration, whereas the flame length increases with the flow velocity. At $U=1$ $\mathrm{cm} / \mathrm{s}$, the flames are almost entirely faint blue. At $40 \% \mathrm{O}_{2}$ and $U=10 \mathrm{~cm} / \mathrm{s}$, the overall flame appears yellow. In other cases (intermediate oxygen concentration and flow velocity), the flame has a blue leading edge and a yellow trailing portion.

The variation of the flame length with flow velocity at different oxygen levels is shown in Fig. 3, where positive velocities correspond to opposed flow, and negative velocities correspond to concurrent flow. As can be seen, in concurrent flow, the flame length increases almost linearly with the flow velocity, and at a given flow velocity, the flame length increases with the oxygen concentration. For opposed flow situation, the flame length barely changes with the oxygen concentration. Its monotonic increase with the flow velocity, however, is clearly observed.

\section{Flame Spread Rates}

As shown in Fig. 2a, when a flame spreads against an opposed oxidizer flow, the flame front is bounded by a clear edge at the upwind side. Accordingly, the flame spread rate can be represented by the travelling speed of the flame edge. Figure 4 presents relative positions of flame leading edge as a function of time for opposed flame spread at $50 \% \mathrm{O}_{2}$ and five different flow velocities. The linear position-time plot shows that a constant flame spread rate for each given flow velocity can be derived as the slope of the plot.

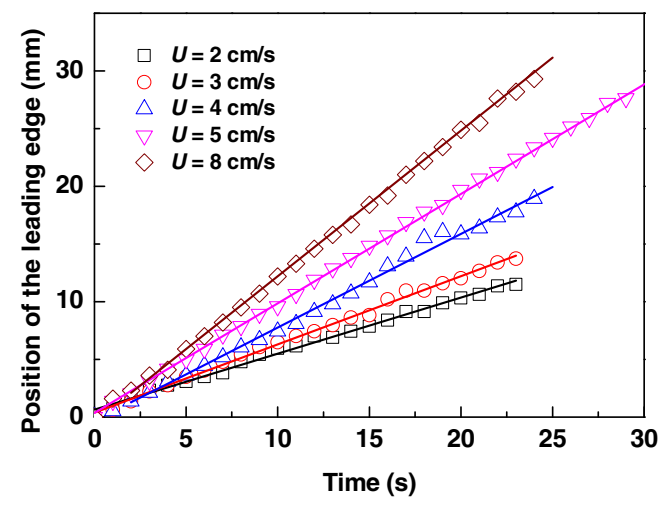

Fig. 4 Position of flame leading edge as a function of time for opposed flame spread at $50 \% \mathrm{O}_{2}$ and different flow velocities

In a concurrent flow, the spreading flame does not develop a clear leading edge at the downwind side. To make the spread rate measurements, following Fernandez-Pello (1979) and Loh and Fernandez-Pello (1984), a surface temperature monitoring method is used. As an example, Fig. 5 shows the time histories of surface temperature for the test at $25 \% \mathrm{O}_{2}$ and $U=10 \mathrm{~cm} / \mathrm{s}$, which are recorded by the thermocouples evenly distributed on the fuel surface. Along its sweeping path, the advancing flame induces a successive temperature rise on the fuel surface. The flame spread rate is determined by measuring the time lag between neighboring thermocouples to reach the same reference temperature. The reference temperature adopted here is represented by the pyrolysis temperature of PMMA, which takes a value of $350{ }^{\circ} \mathrm{C}$, roughly corresponding to the inflection points on the temperature-time curves. Such a pyrolysis temperature value is consistent with those used in the literature (Bhattacharjee et al. 1996; Olson et al. 2009).

Measured spread rates for both opposed and concurrent flames are given in Fig. 6 as a function of flow velocity.

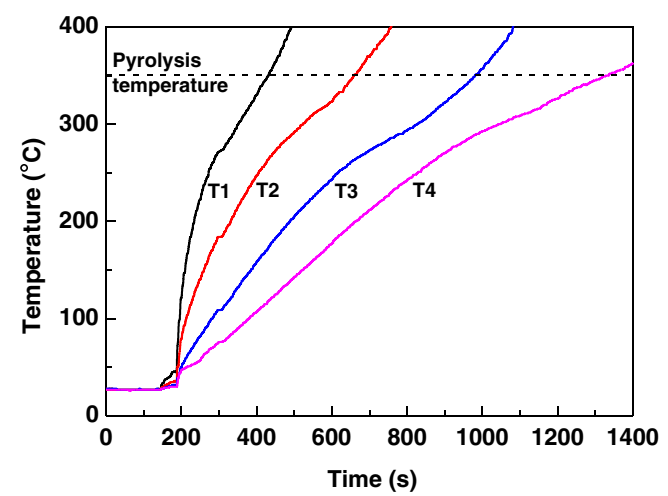

Fig. 5 Histories of surface temperature for concurrent flame spread at $25 \% \mathrm{O}_{2}$ and $U=10 \mathrm{~cm} / \mathrm{s}$ 
Note the vertical coordinate is represented by a logarithmic scale. It is seen that, for the low-velocity flow regime considered, the flame spread rate increases monotonically as the magnitude of the gas velocity increases in both flame spread modes. In opposed flows, the flame spread rate also depends on oxygen concentration, and for all flow velocities it increases with increasing oxygen concentration. In concurrent flows, however, the flame spread rate appears practically independent of the oxygen concentration. Another observation is that, at a given flow velocity, the opposed flame spreads much faster than the concurrent flame, and this trend remains unchanged throughout the flow velocity range considered in the experiments. In particular, at very low gas velocities (i.e., near quenching extinction limits) or at high oxygen concentrations $\left(\geq 30 \% \mathrm{O}_{2}\right)$, the spread rate in opposed spread may be in general one order of magnitude larger than that in concurrent spread. Also shown in Fig. 6 are the microgravity data on opposing flame spread rate over PMMA plates $20 \mathrm{~mm}$ thick, which were measured by Olson et al. (2004) at $50 \% \mathrm{O}_{2}$ and $U=1,5$, and $10 \mathrm{~cm} / \mathrm{s}$. Although the data exhibit a similar trend as the flow velocity increases, they are substantially below the present results for the same oxygen level. One possible factor to consider that could explain this discordance is the fuel sample size adopted in the experiments. In the microgravity tests, the sample is extremely narrow $(6.35 \mathrm{~mm})$. Since lateral heat loss from the flame exerts an influence over a distance of the order of cm in low-velocity flow (Zhang and Yu 2011), the flame is cooled everywhere across its width, resulting in a reduced spread rate. On the contrary, in our experiments the sample has a much larger width $(50 \mathrm{~mm})$, and for the center portion of the flame where the spread rate is measured the side heat loss effect can be avoided. Note that the effect of the sample width on flame spread rate measurements has been extensively observed for thin fuels (Altenkirch et al. 1980; Shih and T'ien 2003; Zhang and Yu 2011).

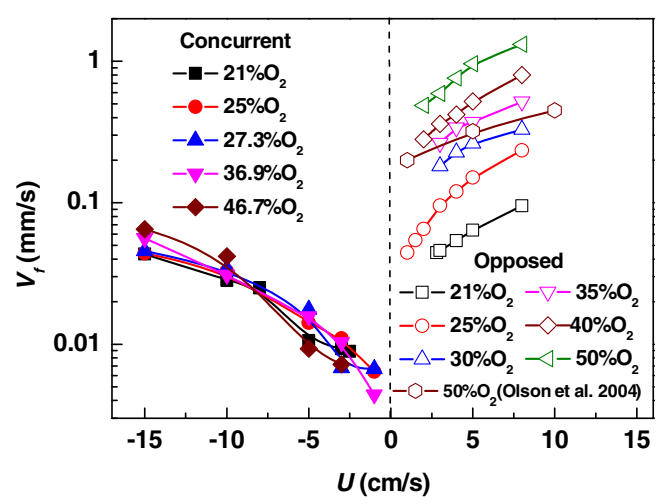

Fig. 6 Flame spread rate as a function of flow velocity for opposed and concurrent spreading flames at different oxygen concentrations. The velocity of opposed flow is defined as positive, and concurrent flow as negative
For opposed flame spread, attempts have been made to correlate the spread rate with the Damköhler number, and a Damköhler number correlation has been successful for both moderate-velocity flow (thermal) regime and high-velocity (kinetic) regime (Fernandez-Pello et al. 1981; Bhattacharjee et al. 1996). In Fig. 7, the experimental results reported in Fig. 6 for opposed flame, together with the data of Fernandez-Pello et al. (1981) for high flow velocities, are presented versus the Damköhler number of Bhattacharjee et al., $D a_{\mathrm{EST}}$. Both sets of the experimental spread rates are normalized with a theoretical spread rate, $V_{f \text {,EST, }}$ predicted by an extended simplified theory (EST) of opposed flame spread (Bhattacharjee et al. 1996). The formula for $V_{f \text {,EST }}$, based on EST, overcame the main drawbacks of the de Ris formula (1969) and performed significantly better than the latter. However, it is noted that the assumptions of infinitely fast chemistry and neglect of radiation are retained in EST, and such that the derived spread rate formula is for the thermal regime. From the results of Fig. 7, it is evident that the non-dimensional flame spread rates, obtained under extensive environmental conditions, collapse almost perfectly onto a universal curve over the entire range of the Damköhler number. The shape of the collapsed curve suggests that three distinct segments may be identified with respect to $D a_{\mathrm{EST}}$. Specifically, for intermediate Damköhler numbers, i.e. $10^{5}<D a_{\mathrm{EST}}<10^{6}, V_{f} \approx V_{f \text {,EST }}$ (i.e., $V_{f}$ $\left./ V_{f \text {,EST }} \approx 1\right)$, and the flame spread is in the thermal regime. For low $D a_{\mathrm{EST}}\left(<10^{5}\right), V_{f}$ is depressed below $V_{f \text {,EST }}\left(V_{f}\right.$ $\left./ V_{f, \mathrm{EST}}<1\right)$ by the finite-rate chemical kinetics, and the flame spread is in the kinetic regime. The third regime, characterized by large $D a_{\mathrm{EST}}\left(>10^{6}\right)$, is indicated by the present experimental data, where the flame spread is in the lowvelocity quenching regime and the spread rate is lowered $\left(V_{f} / V_{f, \mathrm{EST}}<1\right)$ primarily by radiative heat loss.

For concurrent mode, heat transfer models of flame spread (Loh and Fernandez-Pello 1984; Fernandez-Pello

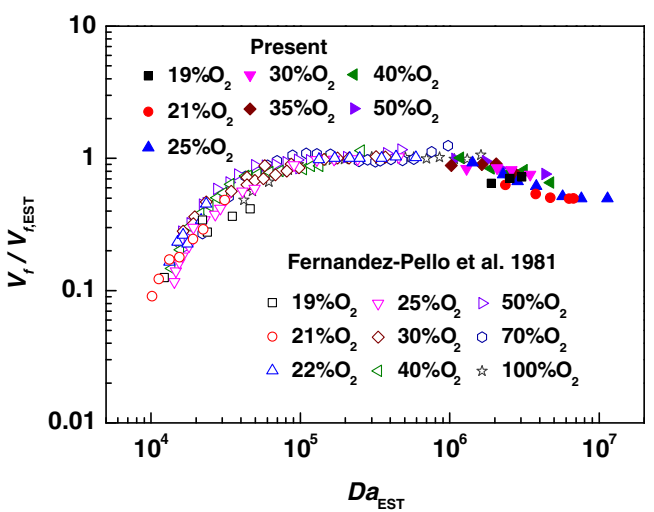

Fig. 7 Correlation of non-dimensional flame spread rate, $V_{f} / V_{f \text {,EST, }}$, with Damköhler number, $D a_{\mathrm{EST}}$, for opposed flame spread. The theoretical spread rate, $V_{f \text {,EST }}$, is predicted by an extended simplified theory of Bhattacharjee et al. (1996) 


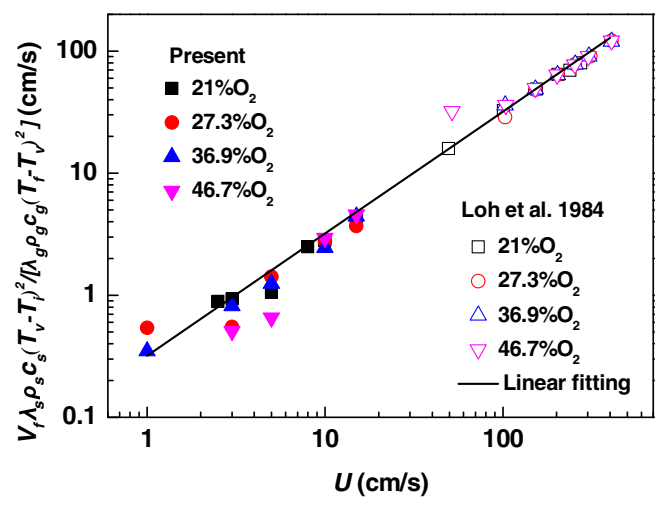

Fig. 8 Experimental spread rate for concurrent spreading flame in a comparison with theoretical prediction

$1979,1984)$ predict spread rates that are linearly proportional to the imposed gas flow velocity: $V_{f} \lambda_{s} \rho_{s} c_{s}\left(T_{v^{-}}\right.$ $\left.T_{i}\right)^{2} /\left[U \lambda_{g} \rho_{g} c_{g}\left(T_{f}-T_{v}\right)^{2}\right]=$ const. Where $T_{f}$ is the adiabatic flame temperature, $T_{v}$ the pyrolysis temperature of the solid, $T_{i}$ the initial temperature of the solid, $\lambda$ the conductivity, $\rho$ the density, and $c$ the specific heat, and the subscripts $s$ and $g$ denote the solid and gas phase respectively. In Fig. 8 a plot of $V_{f} \lambda_{s} \rho_{s} c_{s}\left(T_{v}-T_{i}\right)^{2} /\left[\lambda_{g} \rho_{g} c_{g}\left(T_{f}-T_{v}\right)^{2}\right]$ is presented versus $U$ for the experimental spread rate data reported in Fig. 6 for concurrent flame. Also given in Fig. 8 are the experimental data of Loh and Fernandez-Pello (1984) for high flow velocities, with a linear regression line corresponding to their theoretical model. It is seen that the flame spread rates at different flow velocities agree with the prediction in general, indicating that the heat transfer model captures the main mechanisms controlling the flame spread. On the other hand, the experimental results at low flow velocities can be observed to lie below the theoretical prediction. This deviation may be caused by the neglect of radiative loss in the theoretical model, whereas radiation plays an important role in low-intensity concurrent flame spread (Zhao and T'ien 2015).

\section{Flammability Limits}

Figure 9 plots the flammability boundaries for flames spreading over PMMA under purely opposed and purely concurrent flow conditions, by integrating the results from the present experiments and available published data on opposed flame spread from other groups (Olson et al. 2004; Fernandez-Pello et al. 1981). As can be seen, for the opposed-flow case, the flammability boundary can be constructed over a wide range of flow velocity, and it exhibits a typical U-shaped curve. The left branch of the flammability boundary corresponds to quenching extinction limit in low-velocity flows, where flames are subjected to excessive radiative losses, and the right branch corresponds to blow-off extinction limit in high-velocity flows, where the

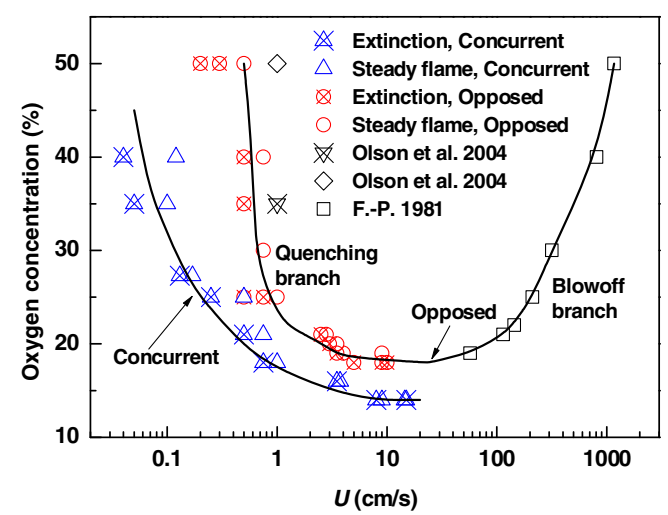

Fig. 9 Flammability boundaries for PMMA in opposed and concurrent flame spread modes

finite chemical kinetics effects play a dominant role. The two branches join together at the bottom of the U-shaped curve, corresponding to the lowest oxygen concentration, below which self-sustained flame spread will not occur for any flow velocities. This lowest oxygen concentration determined from the present study is around $18.5 \% \mathrm{O}_{2}$ for PMMA. For the concurrent flow case, only a left quenching boundary is shown in Fig. 9 since there are no experimental data available for high-velocity gas flows. The lowest oxygen concentration allowing concurrent flame spread in forced flow is estimated to be approximately $14 \% \mathrm{O}_{2}$, substantially below that for opposed flame spread.

The flammability maps illustrated in Fig. 9 indicate that the concurrent spread has a wider flammable range than the opposed case. It is beyond the flammability boundary of opposed spread that a narrow flammable area is added for concurrent spread. In other words, at a given oxygen concentration, concurrent flame spread can survive smaller gas flow velocities, and the limiting flow velocity is always lower than that for opposed spread. In particular, when oxygen concentration is reduced below the lowest oxygen concentration for opposed spread (approximately $18.5 \% \mathrm{O}_{2}$ ), a spreading flame is sustainable in concurrent mode only.

\section{Conclusions}

Systematical experiments are conducted to investigate the flame spread phenomena over a thick PMMA in purely opposed and concurrent flows. A narrow channel apparatus is employed to suppress buoyant flow, such that flame behaviors in the low-velocity flow regime $(U \leq 15 \mathrm{~cm} / \mathrm{s}$ in the present experiments) can be accessed. For both flame spread modes, flame spread rates and flammability limits are measured, using oxygen concentration and forced flow velocity as parameters. The results for opposed flames 
are compared with those for concurrent flames. Concluding remarks are made as follows:

(1) At a given flow velocity, the opposed flame spreads much faster than the concurrent flame in the lowvelocity flow regime considered, and the spread rate in opposed spread may be one order of magnitude larger than that in concurrent spread when flow velocity is very small or oxygen concentration is high. In opposed flows, the flame spread rate also depends on oxygen concentration, while the spread rate of concurrent flame appears less sensitive to the variation of oxygen concentration.

(2) For opposed spread, the non-dimensional flame spread rates are correlated well with the Damköhler number. The entire flame spread domain can be divided into three regimes with respect to $D a_{\mathrm{EST}}$, with the low-velocity quenching regime being indicated by the present experimental data. For concurrent spread, the flame spread rates agree with the theoretical prediction in general. However, it is evident that for both opposed and concurrent flames the spread rates in low-velocity gas flows may deviate from theoretical predictions due to radiative heat loss.

(3) Concurrent flame spread has a wider flammable range than opposed case. Beyond the flammability boundary of opposed spread, there is an additional flammable area for concurrent spread, where the spreading flame is sustainable in concurrent mode only. The lowest oxygen concentration allowing concurrent flame spread in forced flow is estimated to be approximately $14 \% \mathrm{O}_{2}$, substantially below that for opposed flame spread (about $18.5 \% \mathrm{O}_{2}$ ).

(4) The present narrow channel tests provide significant information about the flame spread over thick fuels in low-velocity flows. Considering the shortcomings of a narrow-channel apparatus such as the effect of residual buoyancy, however, more studies, especially microgravity experiments, are clearly needed to validate some of the findings in a quantitative manner.

Acknowledgments This work is funded by the Strategic Pioneer Program on Space Science, Chinese Academy of Sciences, under grant No. XDA04020410. The authors thank Mr. Suide Wang for his assistance in conducting the experiments.

\section{References}

Altenkirch, R.A., Eichhorn, R., Shang, P.C.: Buoyancy effects on flames spreading down thermally thin fuels. Combust. Flame 37, 71-83 (1980)

Altenkirch, R.A., Tang, L., Sacksteder, K., Bhattacharjee, S., Delichatsios, M.A.: Inherently unsteady flame spread to extinction over thick fuels in microgravity. Proc. Combust. Inst. 27, 2515-2524 (1998)

Bhattacharjee, S., Altenkirch, R.A.: Radiation-controlled, opposed flow flame spread in a microgravity environment. Proc. Combust. Inst. 23, 1627-1633 (1990)

Bhattacharjee, S., West, J., Altenkirch, R.A.: Determination of the spread rate in opposed-flow flame spread over thick solid fuels in the thermal regime. Proc. Combust. Inst. 26, 1477-1485 (1996)

de Ris, J.N.: Spread of a laminar diffusion flame. Proc. Combust. Inst. 12, 241-252 (1969)

Fernandez-Pello, A.C.: Flame spread in a forward forced flow. Combust. Flame 36, 63-78 (1979)

Fernandez-Pello, A.C., Ray, S.R., Glassman, I.: Flame spread in an opposed forced flow: The effect of ambient oxygen concentration. Proc. Combust. Inst. 18, 579-589 (1981)

Fernandez-Pello, A.C.: Flame spread modeling. Combust. Sci. Tech. 39, 119-134 (1984)

Hu, W.R., Zhao, J.F., Long, M., Zhang, X.W., Liu, Q.S., Hou, M.Y., Kang, Q., Wang, Y.R., Xu, S.H., Kong, W.J., Zhang, H., Wang, S.F., Sun, Y.Q., Hang, H.Y., Huang, Y.P., Cai, W.M., Zhao, Y., Dai, J.W., Zheng, H.Q., Duan, E.K., Wang, J.F.: Space program SJ-10 of microgravity research. Microgravity Sci. Technol. 26, 159-169 (2014)

Ivanov, A.V., Balashov, Ye.V., Andreeva, T.V., Melikhov, A.S.: Experimental verification of material flammability in space. National Aeronautics and Space Administration, NASA CR-1999-209405 (1999)

Kashiwagi, T., McGrattan, K.B., Olson, S.L., Fujita, O., Kikuchi, M., Ito, K.: Effects of slow wind on localized radiative ignition and transition to flame spread in microgravity. Proc. Combust. Inst. 26, 1345-1352 (1996)

Kumar, A., Shih, H.Y., T'ien, J.S.: A comparison of extinction limits and spreading rates in opposed and concurrent spreading flames over thin solids. Combust. Flame 132, 667-677 (2003)

Loh, H.T., Fernandez-Pello, A.C.: A study of the controlling mechanisms of flow assisted flame spread. Proc. Combust. Inst. 20, 1575-1582 (1984)

Olson, S.L.: Mechanisms of microgravity flame spread over a thin solid fuel: oxygen and opposed flow effects. Combust. Sci. Tech. 76, 233-249 (1991)

Olson, S.L., Kashiwagi, T., Fujita, O., Kikuchi, M., Ito, K.: Experimental observations of spot radiative ignition and subsequent three-dimensional flame spread over thin cellulose fuels. Combust. Flame 125, 852-864 (2001)

Olson, S.L., Hegde, U., Bhattacharjee, S., Deering, J.L., Tang, L., Altenkirch, R.A.: Sounding rocket microgravity experiments elucidating diffusive and radiative transport effects on flame spread over thermally thick solids. Combust. Sci. Tech. 176, 557-584 (2004)

Olson, S.L., Miller, F.J., Jahangirian, S., Wichman, I.S.: Flame spread over thin fuels in actual and simulated microgravity conditions. Combust. Flame 156, 1214-1226 (2009)

Ramachandra, P.A., Altenkirch, R.A., Bhattacharjee, S., Tang, L., Sacksteder, K., Wolverton, M.K.: The behavior of flames spreading over thin solids in microgravity. Combust. Flame 100, 71-84 (1995)

Shih, H.Y., T'ien, J.S.: A three-dimensional model of steady flame spread over a thin solid in low-speed concurrent flows. Combust. Theory Model 7, 677-704 (2003)

T'ien, J.S., Shih, H.Y., Jiang, C.B., Ross, H.D., Miller, F.J., FernandezPello, A.C., Torero, J.L., Walther, D.: Mechanisms of flame spread and smolder wave propagation. In: Ross, H.D. (ed.) Microgravity Combustion: Fire in Free Fall. Academic Press, San Diego (2001) 
West, J., Tang, L., Altenkirch, R.A., Bhattacharjee, S., Sacksteder, K., Delichatsions, M.A.: Quiescent flame spread over thick fuels in microgravity. Proc. Combust. Inst. 26, 1335-1343 (1996)

Xiao, Y., Ren, T., Wang, S.F., Hu, J., Zhao, J.F.: Flame spread over thermally thick fuels in narrow channel apparatus. J. Eng. Thermophys. 31, 1423-1426 (2010). (in Chinese)
Zhang, X., Yu, Y.: Experimental studies on the three-dimensional effects of opposed-flow flame spread over thin solid materials. Combust. Flame 158, 1193-1200 (2011)

Zhao, X.Y., T'ien, J.S.: A three-dimensional transient model for flame growth and extinction in concurrent flows. Combust. Flame 162, 1829-1839 (2015) 